\title{
PENGARUH MEDIA TANAM TERHADAP PERTUMBUHAN dan PERKEMBANGAN DAUN BAWANG (Allium fistulosum L.) BIBIT ANAKAN
}

\author{
Danimaulia Nurraafi Awali ${ }^{1}$, Lusinta Kiswari ${ }^{2}$, dan Suwito Singgih $^{3}$ \\ ${ }^{1}$ Pendidikan IPA, Fakultas Keguruan dan Ilmu Pendidikan, Universitas Tidar, Indonesia. \\ ${ }^{2}$ Pendidikan IPA, Fakultas Keguruan dan Ilmu Pendidikan, Universitas Tidar, Indonesia. \\ ${ }^{3}$ Dosen Fakultas Keguruan dan Ilmu Pendidikan, Universitas Tidar, Indonesia \\ E-Mail: dani.maulianurraafi@gmail.com
}

\begin{abstract}
ABSTRAK
Pengaruh Media Tanam Terhadap Pertumbuhan dan Perkembangan Daun Bawang (Allium Fistulosum L.) Bibit Anakan. Tujuan penelitian, yaitu untuk megetahui pengaruh media tanam terhadap pertumbuhan daun bawang yang ditanam dengan cara memotong bibit anakan. Dalam penelitian, media tanam yang digunakan adalah tanah dan air.

Penelitian dilakukan selama sepuluh hari, terhitung sejak tanggal 29 mei sampai 7 juni 2020. Penelitian dilaksanakan di desa Ajibarang kulon, kabupaten Banyumas. Penelitian menggunakan rancangan penelitian acak lengkap (RAL) dengan cara mengamati perbedaan pada pertumbuhan dan perkembangan bawang daun bibit anakan yang ditanam pada air dan tanah sekali dalam dua hari.

Hasil penelitian menunjukkan bahwa : Air yang digunakan sebagai media tanam mempunyai pengaruh nyata terhadaptinggi daun,dan pertumbuhan daun baru. Tinggi daun saat hari kedua penelitian mencapai $2 \mathrm{~cm}$, dan terus bertambah $2 \mathrm{~cm}$ setiap dua hari. Daun baru muncul terhitung pada hari ke-dua, dan setelah itu muncul di hari ke-empat.

Tanah yang digunakan sebagai media tanam mempunyai pengaruh nyata terhadap Panjang penguningan pada daun. Pada hari ke-enam, salah satu daun menguning hingga $3 \mathrm{~cm}$.
\end{abstract}

Kata kunci : Bawang daun, Bibit anakan, Media tanam.

\begin{abstract}
Effect of Planting Media on Growth and Development of Leek (Allium Fistulosum L.) Seedlings. The purpose of this study was to determine the effect of the planting media on the growth of leeks planted by cutting seedlings. In the research, planting media used were soil and water.

The study was conducted for ten days, starting from May 29 to June 7, 2020. The research was carried out in the village of Ajibarang kulon, Banyumas district. The study used a quantitative research design by observing differences in the growth and development of sapling seedlings that are planted in water and soil once every two days.

The results showed that: Water used as a growing medium has a significant effect on leaf height, and growth of new leaves. Leaf height on the second day of the study reached $2 \mathrm{~cm}$, and continued to increase $2 \mathrm{~cm}$ every two days. New leaves appear on the second day, and after that appear on the fourth day.

Land that is used as a planting medium has a significant effect on the length of yellowing on the leaves. On the sixth day, one leaf turns to $3 \mathrm{~cm}$.
\end{abstract}

Key words : Growing media, Leeks, Seedlings.

\section{PENDAHULUAN}

Bawang daun (Allium fistulosum L.) termasuk salah satu jenis tanaman sayuran genus Allium yang banyak dibudidayakan di Indonesia (Lupita et al.,
2019) Bawang daun juga merupakan salah satu tanaman yang sering digunakan sebagai tambahan rempah pada masakan. Tanaman ini dapat dikonsumsi dalam bentuk segar atau 
dengan kata lain bisa langsung dimakan bersama dengan sayuran lainnya (Fitriadi et al., 2017). Selain menambahkan aroma yang khas, bawang daun juga memberi rasa sedap pada masakan karena memiliki aroma yang khas dan biasa digunakan sebagai pengharum masakan (Fitriadi et al., 2017). Bawang daun juga mengandung vitamin $\mathrm{A}$ dan $\mathrm{C}$ yang tinggi, sehingga sangat bermanfaat bagi kesehatan. Selain itu, karena aromanya pula daun bawang dapat difungsikan sebagai tanaman pengusir hama dengan cara ditumpangsarikan dengan tanaman lain karena menurut (Dadang, 1999) pada (Nirmayanti, 2004) tanaman repellent/penolak organisme pengganggu tanaman (OPT) akan melindungi tanaman didekatnya dengan bau-bauan yang dikeluarkan oleh tanaman tersebut, bentuk dan warna daun atau bunga yang khas yang tidak disukai hama, sehingga hama akan menjauh dari tanaman utama (Dadang, 1999 ). Disamping berfungsi sebagai bahan masakan dan obat pengusir hama, bawang daun juga dapat dimanfaatkan sebagai obat luka bakar (Sunaryono, 2012). Dengan demikian, bawang daun cukup diminati masyarakat di seluruh dunia dan mudah ditemukan (Fitriadi et al., 2017). Bahkan, bawang daun termasuk sayur unggulan di daerah Kalimantan (Ira et al., 2020). Hal tersebut karena bawang daun memiliki daya adaptasi yang relatif luas terhadap daerah lingkungan tempat tumbuhnya (Alfiana, 2018).

Tanaman ini tumbuh di daerah dengan ketinggian 250-1500 mdpl yang mana bisa dikatakan bahwa tanaman ini bisa hidup di dataran rendah maupun dataran tinggi, serta curah hujannya 150$200 \mathrm{~mm} /$ tahun (Lestari, 2016).

Menurut Rahmat (1995) struktur tubuh bawang daun terdiri atas akar, batang semu dan daun. Sedangkan pada usia tertentu menghasilkan bunga dan biji. Batang semu daun bawang terbentuk atas pelepah daun yang saling menutupi. Batang semu pada bagian atas berwarna putih bersih sedangkan pada bagian bawah berwarna putih kehijauan. Sifat hidup bawang daun ini merumpun, yakni dengan membentuk anakan-anakan baru (Lestari, 2016). Anakan-anakan tersebut akan terus tumbuh dan berkembang.

Pertumbuhan berarti pertambahan ukuran. Karena Organisme multisel tumbuh dari zigot, pertambahan itu bukan hanya dalam volume, tetapi juga dalam bobot, jumlah sel, banyaknya protoplasma dan tingkat kerumitan (Salisbury dan Ross, 1991).

Dalam pertumbuhan dan perkembangannya, bawang daun memerlukan beberapa faktor yang cukup, salah satunya yaitu air. Menurut Bambang (2005), pengairan bawang daun cukup dilakukan seperlunya. Pengairan yang berlebihan dapat menyebabkan busuk akar sehingga tanaman menjadi layu dan akhirnya mati. Sebaliknya, pengairan yang kurang juga menyebabkan pertumbuhan bawang daun lambat, daun cepat tua, dan tanaman menderita klorosis dan antosianensis. Pengairan yang tepat pada daun bawang akan meningkatkan pertumbuhan generatif dan vegetatif. Teknik pengairan dapat di siasati dengan pemilihan media tanam.

Media tanam merupakan media atau tempat dimana tanaman dan biji dapat tumbuh dan berkembang didalamnya. Contoh media tanam seperti tanah, air, kapas, kompos, dan sejenis lainnya. Dalam kehidupan zaman seperti saat ini, di kehidupan sehari-hari atau dalam perkebunan, tanah selalu menjadi media tanam bagi benih yang akan ditanam. Namun, adanya pengalihfungsian lahan pertanian ke lahan non-pertanian menjadi kendala untuk bertanam. Media tanam merupakan media tumbuh bagi tanaman yang dapat memasok sebagian unsur-unsur hara yang 
dibutuhkan oleh tanaman. Sumber unsur hara dapat berupa pupuk kandang, limbah ternak, kompos, maupun limbah. Media tanam tersebut berfungsi untuk membantu perkembangan akar (Novitasari, 2018).

Media tanam atau media tumbuh merupakan salah satu unsur penting dalam menunjang pertumbuhan tanaman secara baik. Sebagian besar unsur-unsur hara yang dibutuhkan tanaman dipasok melalui media tanaman (Efriyadi, 2018).

Tujuan dari penelitian ini adalah untuk mengetahui pengaruh media tanam terhadap pertumbuhan dan perkembangan bawang daun selama sepuluh hari

\section{METODA PENELITIAN}

\subsection{Tempat dan Waktu}

Penelitian dilakukan di desa Ajibarangkulon, kecamatan Ajibarang, kabupaten Banyumas selama sepuluh hari, terhitung sejak tanggal 29 mei sampai 7 juni 2020 .

\subsection{Bahan dan Alat}

Bahan yang digunakan dalam penelitian ini adalah tanah, air, setek/anakan bawang daun, dan botol air mineral.

Alat yang digunakan dalam penelitian ini adalah sekop mini, gayung untuk mengisi air dan menyiram tanaman, pisau, penggaris dan alat tulis.

\subsection{Rancangan Penelitian}

Penelitian dilakukan menggunakan rancangan penelitian acak lengkap (RAL) dengan cara mengamati perbedaan pada pertumbuhan dan perkembangan bawang daun bibit anakan yang ditanam pada air dan tanah sekali dalam dua hari.

\subsection{Pelaksanaan Penelitian}

Kegiatan penelitian meliputi : (1)

Penyiapan media tanam
Penyiapan anakan bawang daun dengan memotong $2 / 3$ batang semu (3) Penanaman anakan bawang daun

(4) Perawatan meliputi penyiraman pada bawang daun di media tanah dan penyiangan.

\subsection{Pengumpulan Data}

Data utama yang dikumpulkan sebagai berikut :(1) Tinggi tanaman setelah 2,4,6,8 dan 10 setelah penanaman (2) pertumbuhan daun baru pada hari ke 2,4,6,8 dan 10 setelah penanaman (3) Panjang penguningan daun pada hari ke 2,4,6,8 dan 10 setelah penanaman.

\subsection{Analisis Data}

Untuk mengetahui pengaruh media tanam terhadap perkembangan dan pertumbuhan bawang daun anakan dilakukan dengan menganalisis data dengan menggunakan cara deskriptif.

\section{HASIL PENELITIAN DAN PEMBAHASAN}

\subsection{Tinggi tanaman}

Hasil penelitian menunjukkan bahwa bawang daun yang ditanam melalui media air cenderung lebih tinggi dari bawang daun yang ditanam di media tanah. Hal ini disebabkan karena kadar air yang berbeda. Lebih banyak kadar air yang diserap oleh akar, maka akan sempurna dan lebih cepat pula pertumbuhannya. Menurut Najiati dan Danarti (1998), Air dalam media tanam akan diserap oleh akar V. sinensis kemudian masuk ke dalamtanaman. Selanjutnya, air akan menuju ke daun untuk menjalankan fotosintesis. Hasil fotosintesis kemudian digunakan oleh tanaman untuk proses pertumbuhan. Peranan air bagi kehidupan tanaman antara lain, air sebagai pelarut unsur hara di dalam tanah sehingga tanaman dapat dengan mudah mengambil hara melalui 
pembuluh xilem. Selain itu, air juga berperan dalam proses fotosintesis. Air akan melarutkan glukosa sebagai hasil fotosintesis dan mengangkutnya ke seluruh tubuh tumbuhan melalui pembuluh floem. Hasil fotosintesis iniakan digunakan tumbuhan untuk proses pertumbuhannya.

\subsection{Pertumbuhan daun baru}

Hasil penelitian menunjukkan bahwa pertumbuhan daun baru pada daun bawang yang berada di media tanam air memiliki pertumbuhan daun yang lebih cepat dari pertumbuhan daun bawang pada daun bawang yang berada pada media tanah. Hal ini disebabkan karena lebih banyaknya kandungan air yang diserap oleh daun bawang pada media air. Dugaan ini diperkuat oleh hasil penelitian El Balla dkk. (2013) mengenai efek kekeringan terhadap pertumbuhan tanaman bawang merah seperti jumlah daun, diameter umbilicus (bentuk bunga), jumlah bunga dalam umbilicus, dan jumlah biji perbunga berkurang.

\subsection{Panjang penguningan pada daun}

Hasil penelitian menunjukkan bahwa bawang daun yang tumbuh menggunakan media tanah memiliki daun yang lebih cepat menguning. Berbeda dengan bawang daun yang tumbuh menggunakan media air. Bawang daun yang tumbuh pada tanah memiliki daun yang menguning sepanjang $3 \mathrm{~cm}$ pada hari ke enam setelah penanaman. Sedangkan bawang daun yang tumbuh menggunakan air belum mengalami penguningan. Hal ini diduga karena peranan akar dalam penyerapan air.

Penguningan pada bawang daun yang tumbuh menggunakan tanah memiliki salah satu daun yang mengguning dengan Panjang $3 \mathrm{~cm}$ pada hari ke-enam. hal ini diduga karena penyerapan air oleh akar terhalang tanah, sehingga kadar air yang diserap sedikit.
Hal tersebut menghambat proses fotosintesis dan pembentukan klorofil, sedangkan pada bawang daun yang tumbuh menggunakan air tidak mengalami penguningan selama 10 hari. Menurut Song dkk. (2011) Respons tanaman terhadap kekurangan air pada umumnya ditunjukkan dengan penurunan konsentrasi klorofil daun. Penurunan kandungan klorofil pada saat tanaman kekurangan air berkaitan dengan akitivitas perangkat fotosintesis dan menurunkan laju fotosintesis tanaman. Kekurangan air akan mempengaruhi kandungan dan organisasi klorofil dalam kloroplas pada jaringan

\section{KESIMPULAN}

Perbedaan penggunaan media tanam dapat mempengaruhi tinggi bawang daun, pertumbuhan daun baru dan Panjang penguningan pada daun. Pada media tanam air, dan bawang lebih tinggi, pertumbuhan daun baru lebih cepat dan Panjang penguningan pada daun lebih pendek dibanding daun bawang yang ditanam menggunakan media tanah. Semakin banyak kadar air yang dapat diserap oleh daun bawang, maka semakin cepat pertumbuhan selnya, sehingga menyebabkan tinggi daun dan pertumbuhan daun baru lebih optimal. Selain itu, penyerapan kadar air yang cukup akan memperkecil potensi kekeringan, sehingga proses fotosintesis dan pembentukan klorofil berjalan dengan lancar. 


\section{DAFTAR PUSTAKA}

Alfiana, I. (2018). Pengaruh dosis pupuk kandang sapi terhadap pertumbuhan dan hasil bawang daun asal biji. (Skripsi dipublikasikan). Universitas Mercu Buana Yogyakarta.

Anggi, I. Y., \& Mohamad. N (2019). Komposisi Media Tanam Dan Interval Penyiraman POC Terhadap Pertumbuhan Tanaman Bawang Daun Pada Sistem Vertikultur. Exact Papers in Compilation, 1(3), 129-136.

Cahyono, B. (2005). Seni Budi Daya Bawang Daun. Yogyakarta: Kanisius.

Efriyadi, O. (2018). Pengaruh Perbedaan Jenis Media Tanam Hidroponik terhadap Pertumbuhan Pakcoy (Brassica rapa) dan Kangkung (Ipomoea aquatic). Proceeding of The URECOL, 675-681.

El Balla, M. D., Hamid, A. A., \& Abdelmageed, A. H. A. (2013). Effects of time of water stress on flowering, seed yield and seed quality of common onion (Allium cepa L.) under the arid tropical conditions of Sudan. Agricultural Water Management, 121, 149-157.
Fitriadi, S., Triatmoko, E., \& Putri, R. A. S. (2017). Kontribusi tenaga kerja dalam keluarga terhadap pendapatan usahatani bawang daun (Allium fistulosum L.) di Kelurahan Landasan Ulin Utara Kota Banjarbaru. ZIRAA'AH, 42 (3), 193-199.

Ira, M., Zuraida, T,M., \& Ahmad, K. (2020). Pengaruh Pemberian Kapur Dolomit dan pupuk daun terhadap pertumbuhan bawang daun (Allium fistulosum L.) pada tanah gambut. Agroekotek View, 3(1). 45-54.

Lestari, R. (2017). Respons tanaman bawang daun (Allium fistulosum L.) terhadap aplikasi pupuk daun pada berbagai jarak tanam. (Skripsi dipublikasikan). Sekolah Tinggi Ilmu Pertanian (STIPER) Dharma Wacana Metro.

Lupita, L., Riyanto., \& Bambang, N. (2019) Pengaruh Total dissolved solid terhadap pertumbuhan dan hasil bawang daun. Naskah Publikasi Program Studi Agroteknologi.

Najiyati S. dan Danarti. (1990). Petunjuk Mengairi dan Menyiram tanaman. Jakarta: penebar swadaya. 
Nirmayanti, F. (2014). Pengaruh Beberapa Jenis Tanaman Pendamping Terhadap Hama Phyllotreta Striolata F. (Coleoptera: Chrysomelidae) Pada Budidaya Sawi Hijau Organik. Jurnal HPT, 3(2), 69-75.

Novitasari, D. (2018). Respons pertumbuhan dan produksi selada (Lactuca sativa L.) terhadap perbedaan komposisi media tanam dan interval waktu aplikasi pupuk organik cair. (Skripsi dipublikasikan). Universitas Lampung, Bandar Lampung.

Rukmana, I. H. R. (1995). Daun Bawang. Yogyakarta: Kanisius.

Song, A. N., \& Banyo, Y. (2011). Konsentrasi klorofil daun sebagai indikator kekurangan air pada tanaman. Jurnal ilmiah sains, 11(2), 166-173.

Sunaryono, H. (2012). Bercocok Tanam Bawang Daun. Jakarta: Penebar Swadaya. 